\title{
Wireless energy harvesting for rotor instrumentation in electrical machines
}

\author{
M R Tatlow, R A McMahon, S Abdi \\ *University of Cambridge, Engineering Department, 9 JJ Thomson Avenue, Cambridge, CB3 0FA.mrt39@cam.ac.uk
}

Keywords: Energy harvesting, rotor instrumentation.

\begin{abstract}
In order to perform experiments on electrical machines, it is desirable to measure rotor parameters such as currents and temperatures. A Bluetooth module have been developed which sends data from the rotor, however this module is battery powered, and therefore the duration of the tests is limited. This paper presents a solution to this problem, by developing a rotor-mounted power supply system which can harvest energy from leakage magnetic flux inside the machine, by fixing an external loop to the rotor and making use of induced voltages in the loop. A full-bridge rectifier, boost converter and battery charging module was developed to supply sufficient power to the Bluetooth module.
\end{abstract}

\section{Introduction}

The recent growth of variable speed drives (VSD) has led to a need for a device which can measure rotor data wirelessly. A system currently exists [1] [2] which measures rotor signals and transmits the data using Bluetooth. However, this system is battery powered which limits its practicality as batteries are bulky and require regular recharging. At the same time there is unutilized magnetic energy in the end-winding region of the rotor, but extracting stable DC power from this field is complex due to the varying nature of the magnetic field (e.g. strength, frequency, etc) and the existence of a high level of electromagnetic noise and interference. This paper presents a wireless energy harvesting system which utilizes the rotor's magnetic energy to power the Bluetooth module. The rotor instrumentation system has been demonstrated in a Brushless Doubly Fed (Induction) Machine (BDFM), a machine extensively researched at the University of Cambridge, but the technology is applicable to other VSD's.

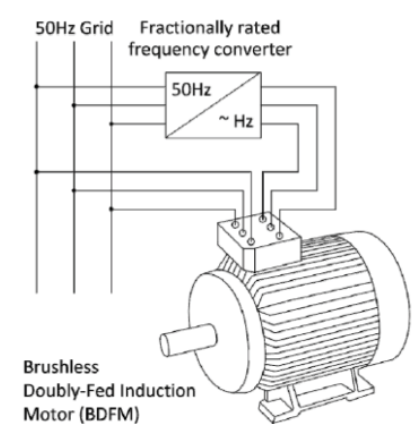

Figure 1 Block diagram of BDFM

\section{Energy harvesting technique}

The test machine is a $4 / 8$ pole BDFM [3] (Figure 1), with parameters described in Table 1.

\begin{tabular}{|l|l|}
\hline Stack length & $190 \mathrm{~mm}$ \\
\hline Airgap diameter & $175 \mathrm{~mm}$ \\
\hline Stator poles & 4,8 \\
\hline Rotor type & Nested-loop \\
\hline Speed range & $200-800 \mathrm{rev} / \mathrm{min}$ \\
\hline Rated torque & $112 \mathrm{Nm}$ \\
\hline
\end{tabular}

Table 1 Parameters of D180 BDFM

The energy harvesting system was designed to meet the specifications outlined in Table 2. The output current of $200 \mathrm{~mA}$ is the estimated maximum current consumption of the Bluetooth module operating at $5 \mathrm{~V}$. This is conservatively estimated, and if lower data rates are acceptable a lower power requirement would be adequate.

\begin{tabular}{|l|l|}
\hline Input voltage range & $0.75-1.8 \mathrm{~V} \mathrm{rms}$ \\
\hline Input frequency range & $20-50 \mathrm{~Hz}$ \\
\hline Output voltage & $6 \mathrm{~V} \mathrm{dc}$ \\
\hline Output current & $200 \mathrm{~mA}$ \\
\hline Run time with no input power & $>10$ minutes \\
\hline Temperature rating & $85^{\circ} \mathrm{C}$ \\
\hline
\end{tabular}

Table 2 Specification for rotor energy harvesting power supply

Two different methods for extracting energy from the rotor, as shown in Figure 2, were investigated and calculations were performed to determine the expected voltages and frequencies that each option would yield. Other practical issues such as construction, ease of retro-fitting to an existing rotor and mechanical robustness were also considered. The two options are described below. 


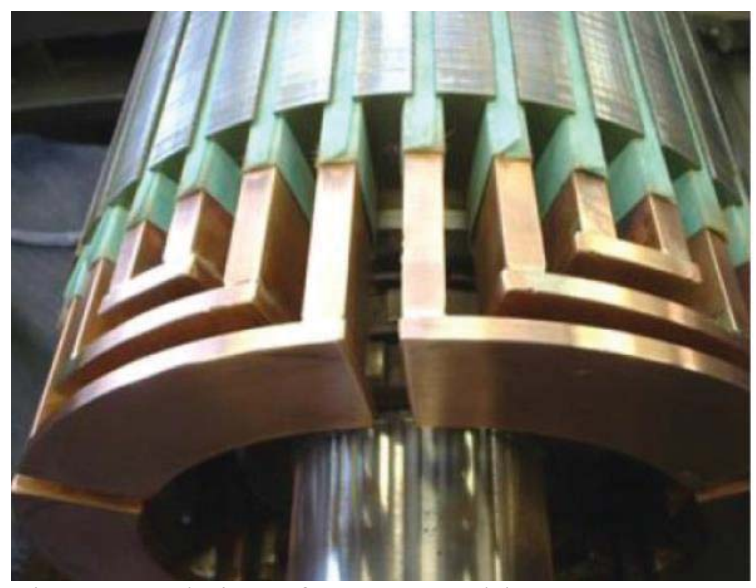

Figure 2 End view of D180 nested-loop BDFM rotor

\subsection{End-winding transformer}

A core of magnetic material is fastened around the end winding of a rotor bar, and several turns of wire are wound around the core, as shown in Figure 3.

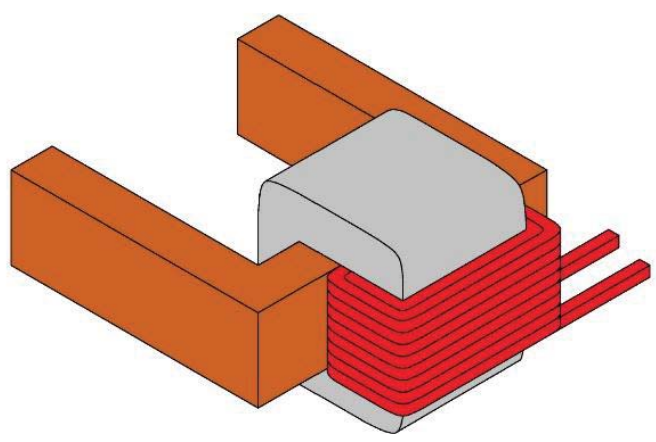

Figure 3 End winding transformer

The magnetisation $H$, is given by

$$
H=\frac{I_{b a r}}{l_{m}}
$$

Where $I_{b a r}$ is the current in the rotor bar, and $l_{m}$ is the mean magnetic path length of the core. The current in the outer loop of the rotor of the test machine varies between $20 \mathrm{~A} \mathrm{rms}$ at zero torque, up to $1000 \mathrm{~A} \mathrm{rms}$ when running at full load. If the magnetic path length is estimated to be $100 \mathrm{~mm}$, this gives $H=200 \mathrm{~A} / \mathrm{m}$ at no load, varying up to $10^{4} \mathrm{~A} / \mathrm{m}$ at full load. If the core is manufactured from the same electrical steel as the machine itself, this corresponds to a magnetic field in the core of approximately $1.2-1.8 \mathrm{~T}$ respectively [4]. The core would therefore be heavily saturated as soon as the machine is run at any meaningful torque.

Therefore, the voltage produced will not be sinusoidal, but will consist of short pulses of alternating polarity each time the flux in the core reverses direction. As the bar current is increased, the pulses will become progressively shorter, but higher in amplitude, and if these pulses are rectified and filtered, the mean DC voltage can be calculated. Assuming the bar current is sinusoidal with peak amplitude $\hat{I}$, then:

$$
H=\frac{\hat{I}}{l_{m}} \cos \omega t
$$

Since the core will saturate, the non-linear properties of the material must be taken into account. Neglecting the effects of hysteresis, it is assumed that the magnetic field density $B$ is given by $b(H)$ such that $b(-H)=-b(H)$. Then

$$
B=b\left(\frac{\hat{I}}{l_{m}} \cos \omega t\right)
$$

And the instantaneous induced emf $E$ is given by

$$
E=-N \frac{d \varphi}{d t}=-N A \frac{d B}{d t}
$$

Where $A$ is the cross-sectional area of the core and $N$ is the number of turns. After rectifying and filtering, the DC voltage produced can be found by integrating over half a cycle of the AC waveform:

$$
\begin{gathered}
V_{D C}=\frac{N A}{\pi} \int_{0}^{\pi} \frac{d B}{d t} d(\omega t) \\
=\frac{N A \omega}{\pi}\left[b\left(\frac{\hat{I}}{l_{m}} \cos \omega t\right)\right]_{0}^{\pi} \\
=-\frac{N A \omega}{\pi}\left[b\left(-\frac{\hat{I}}{l_{m}}\right)-b\left(\frac{\hat{I}}{l_{m}}\right)\right] \\
=\frac{2 N A \omega b\left(\frac{\hat{I}}{l_{m}}\right)}{\pi}
\end{gathered}
$$

Putting in some likely estimates, $N=100, A=180 \mathrm{~mm}^{2}$ gives the following voltages:

- $\hat{I}=28 \mathrm{~A}, \omega=46 \pi \mathrm{rad} / \mathrm{s}(23 \mathrm{~Hz}), V_{D C}=2.15 \mathrm{~V}$

- $\hat{I}=1410 \mathrm{~A}, \omega=88 \pi \mathrm{rad} / \mathrm{s}(44 \mathrm{~Hz}), V_{D C}=5.86 \mathrm{~V}$

These are practical voltages to work with, and the exact range of voltages can be adjusted by varying the number of turns. However, there are other issues with this method:

- The rapidly reversing magnetic flux may cause large voltage spikes, up to $900 \mathrm{~V}$, at the input terminals of 
the rectifier, so the circuitry and windings should be designed to support these large voltages.

- The filter inductor will have to be physically large and heavy to provide effective filtering down to the minimum rotor frequency of $23 \mathrm{~Hz}$. This is particularly undesirable since it will be spinning at high speeds and will therefore experience high centripetal forces and take up space when mounted onto the rotor.

- Designing the core will be tricky. The core must be in two parts, to allow retrofitting to an existing rotor, and must be reliably secured to handle the centripetal forces experienced when rotating at high speed.

For these reasons it was felt that this method would be too challenging to implement practically.

\subsection{Additional rotor loop}

Another approach is to fasten wires, by making taps at specific locations on the nested loop rotor, exploiting the EMFs that would be induced around the rotor loops (Figure 4). The pitch angle of the external loop can be selected to couple to the magnetic field of either or both stator windings. In this case a pitch angle of $90^{\circ}$ is attractive because this will couple fully to the 4-pole windings (which has a constant amplitude because it is connected directly to the grid), but not to the 8-pole winding (the amplitude of which varies depending on the voltage supplied by the power converter).

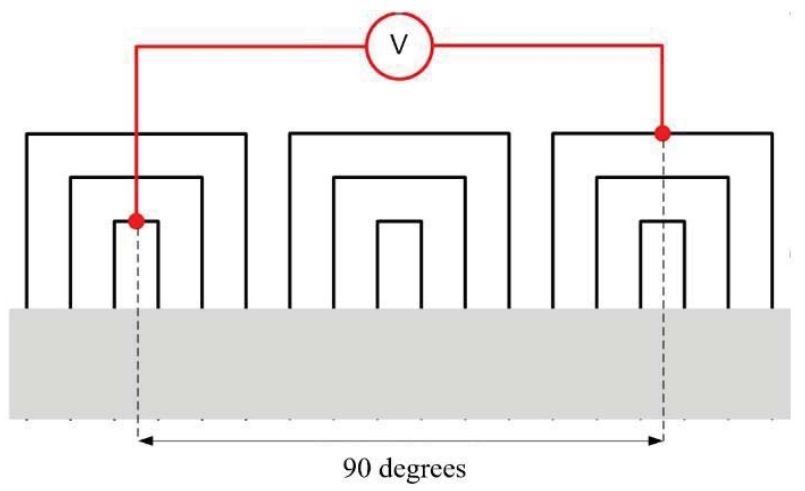

Figure 4 Rotor taps to form external rotor loop

Applying Faraday's law to the machine, the voltage $E_{r m s}$ induced in a single loop that fully couples to the air-gap field $B_{r m s}$ is given by:

$$
E_{r m s}=\frac{l \omega d}{p} B_{r m s}
$$

Where $l$ is the stack length of the machine, $d$ is the air-gap diameter, $p$ is the number of pole-pairs for the relevant winding, and $\omega$ is the frequency in the rotor reference frame.
In [5] the measured air-gap field of the 4-pole winding was $0.30 \mathrm{~T}$ at $230 \mathrm{~V}$. The frequency in the rotor reference fame is given by $\omega=\omega_{\mathrm{s}}-\mathrm{p} \omega_{\mathrm{r}}$, where $\omega_{\mathrm{s}}$ is the electrical frequency applied to the relevant stator winding, and $\omega_{\mathrm{r}}$ is the mechanical speed of the rotor. Using Equation (9), the calculated voltage and frequency expected in the external rotor loop is given in Table 3.

\begin{tabular}{|c|c|c|}
\hline Rotor speed (rpm) & Voltage $(\mathrm{V}$ rms) & Frequency $(\mathrm{Hz})$ \\
\hline 200 & 1.39 & 43.3 \\
\hline 500 & 1.07 & 33.3 \\
\hline 800 & 0.75 & 23.3 \\
\hline
\end{tabular}

Table 3 Voltage and frequencies induced in a single rotor loop of $90^{\circ}$ pitch

This method has the advantage of being physically robust (provided the taps are securely fastened to the rotor bars) but the induced voltage is low and there is no possibility of using additional turns to increase the voltage. A step up converter can, however, be used to raise the voltage to a more useful level. Ultimately it was decided to use this method due to its mechanical simplicity, despite the low voltage levels.

\section{Finite element analysis}

The induced voltage in a rotor loop can also be determined by finite element (FE) analysis. The D180 BDFM machine is modelled in synchronous mode of operation (Figure 5) at full load operating conditions (Table 1). A single-turn coil with a pitch angle of $90^{\circ}$ is wound around the rotor slots through the machine stack length in the FE mesh, to simulate the external loop formed from taps to the rotor bars, so that coupling with the 8-pole air gap field is eliminated. However, because the air gap field always contains some degree of space harmonics as shown in Figure 6, higher time harmonics will still be present in the induced voltage in the external loop. Figure 7 shows the induced voltages in the external rotor coil when the rotor rotates at different speeds. The rms values of the induced voltages, as well as induced main and harmonic frequencies obtained by FE are shown in Table 4. Harmonic content with magnitudes less than $5 \%$ of the main frequency are neglected. 


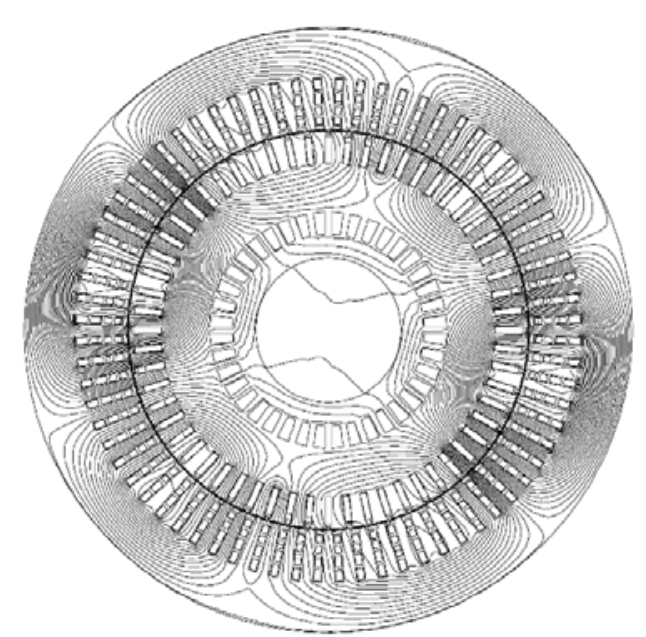

Figure 5 Distribution of flux density in the D180 BDFM iron circuit in synchronous mode of operation

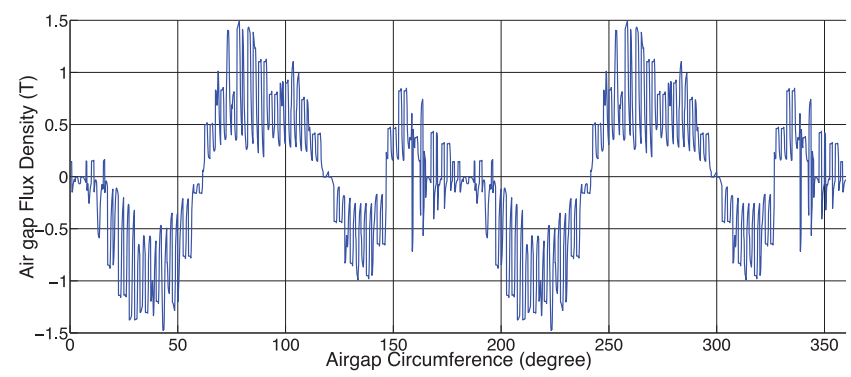

Figure 6 Space distribution of air gap flux density in D180 BDFM in synchronous mode of operation

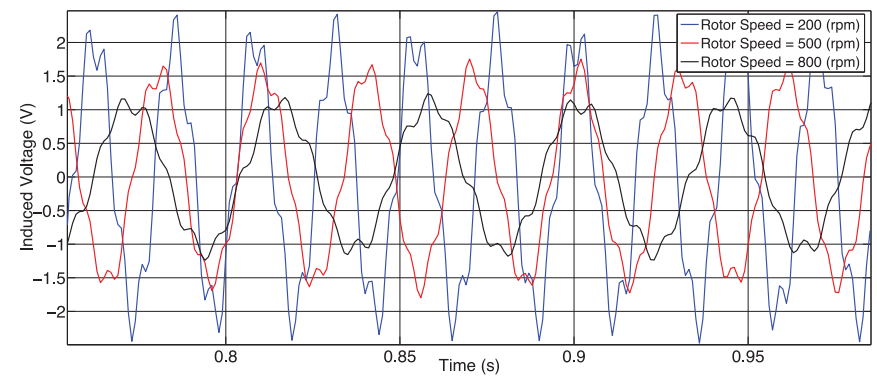

Figure 7 Induced voltages in the additional loop mounted in rotor slots with a pitch angle of $90^{\circ}$

\begin{tabular}{|c|c|c|c|}
\hline $\begin{array}{c}\text { Rotor speed } \\
(\mathrm{rpm})\end{array}$ & $\begin{array}{c}\text { Voltage } \\
(\mathrm{V} \mathrm{rms})\end{array}$ & $\begin{array}{c}\text { Main freqeuncy } \\
(\mathrm{Hz})\end{array}$ & $\begin{array}{c}\text { Harmonic } \\
\text { Frequencies }(\mathrm{Hz})\end{array}$ \\
\hline 200 & 1.49 & 43.3 & 115,196 \\
\hline 500 & 1.12 & 33.3 & 93,184 \\
\hline 800 & 0.79 & 23.3 & 86,148 \\
\hline
\end{tabular}

Table 4 Voltages and frequencies induced in a single rotor loop of $90^{\circ}$ pitch obtained by $\mathrm{FE}$ analysis

\section{Design of energy harvesting module}

Comparing Table 3 and Table 4, it can be seen that the expected voltages and frequencies induced in an external rotor loop are very similar. Based on these predictions, the energy harvesting module can be designed and built.

Due to the low input voltage $(0.75-1.8 \mathrm{~V})$, a passive rectifier could not be used because of the diode voltage drop. Therefore, a full-bridge MOSFET synchronous rectifier was built, with a switching frequency of $50 \mathrm{kHz}$, controlled by a microcontroller.

A small Nickel-Metal Hydride rechargeable battery is used to power the system when the rotor is idle $(170 \mathrm{~mA}$ at $5 \mathrm{~V}$ for 10 mins). The battery can withstand a continuous trickle charge, so accurate charge management is not required. The battery is rated at $85{ }^{\circ} \mathrm{C}$, and although temperatures of up to $150{ }^{\circ} \mathrm{C}$ can be expected on the rotor, this was the best high temperature battery available commercially.

A closed-loop controller (Figure 10) was designed to regulate the power flow through the rectifier. Two feedback loops were used to control the switching of the rectifier, an inner loop to regulate the input current, and an outer loop to regulate the battery current.

The Bluetooth module is currently being built based on the design in [2], it will be powered from the output of the converter module and will be able to measure rotor temperature and have the necessary integrator and filter circuits for the Rogowski coils.

A hexagonal bracket (Figure 8) was built to allow the three converter circuit boards (Figure 9), one Bluetooth module and the possibility of two other circuit boards, if required, to be secured to the rotor shaft.

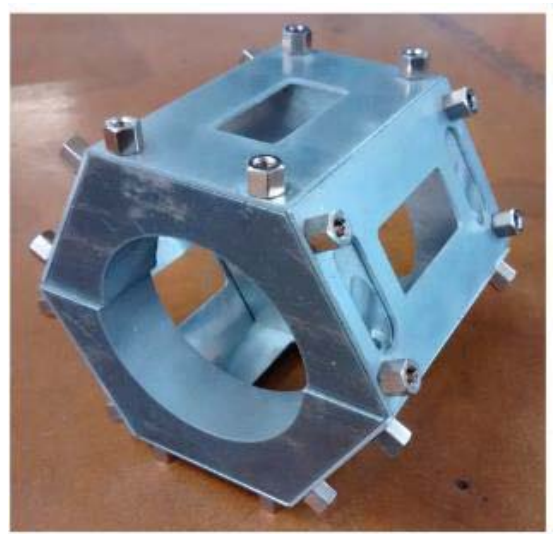

Figure 8 Hexagonal bracket for mounting the circuit boards to the rotor shaft 


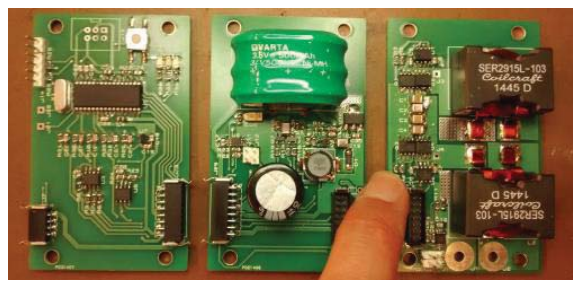

Figure 9 PCBs of converter module.

L-R: Microcontroller board, battery charging circuit, synchronous rectifier

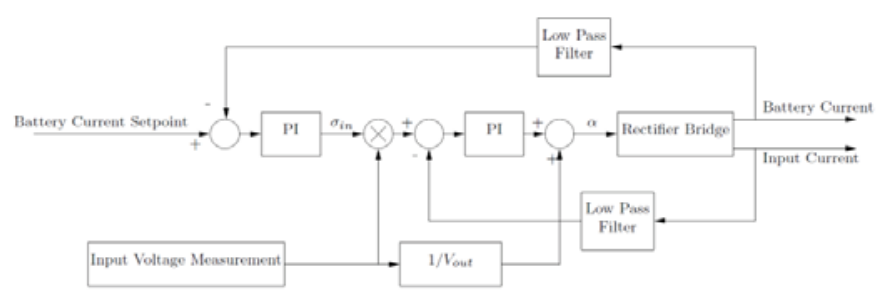

Figure 10 Closed loop controller for converter

\section{Results}

The converter module was tested on a bench setup, with a variable voltage and frequency source to simulate the induced voltage from the rotor. The battery current was set to a $25 \mathrm{~mA}$ trickle charge. The maximum available load current is plotted in Figure 11. The $200 \mathrm{~mA}$ target was achieved at an input voltage of $0.74 \mathrm{~V}$ and higher which meets the specifications outlined in Table 2. Varying the input frequency from 20 to $50 \mathrm{~Hz}$ was found to have no measurable effect on performance. The efficiency of the energy harvesting module is shown in Figure 12.

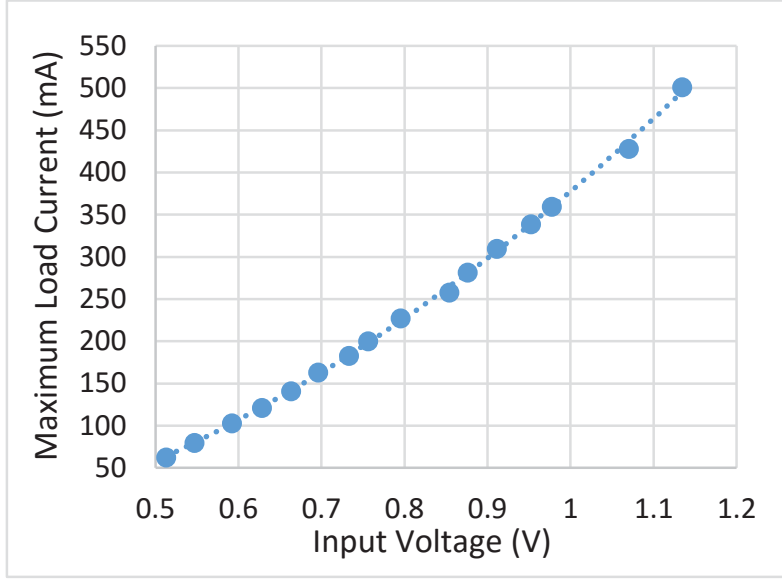

Figure 11 Maximum load current delivered from converter module over an input voltage range with a battery trickle charge of $25 \mathrm{~mA}$

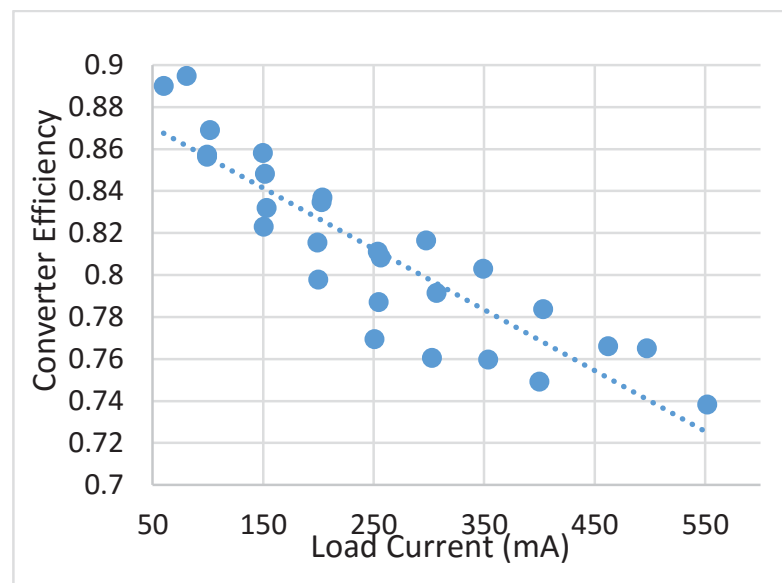

Figure 12 Efficiency of converter module with a battery trickle charge of $25 \mathrm{~mA}$

\section{Conclusions}

The aim of the project was to build an energy harvesting system and Bluetooth module which can be mounted on the rotor of a VSD to measure and transmit quantities such as rotor current, flux and temperature. Two techniques were investigated and assessed based on their output voltage and physical constraints. The best solution was to insert physical taps between loops in the rotor such that small EMF voltages are induced in an external circuit. A synchronous rectifier was designed to convert the small AC voltage into a stable DC voltage, a further DC-DC boost converter raised this voltage for battery charging and to power the microcontroller and Bluetooth module. An important consideration for the design of the energy harvesting module is finding a rechargeable battery which can withstand the high temperatures associated with the rotor, if a suitable battery cannot be found it may be necessary to insulate the battery and keep it in cooling air. The energy harvesting module performed to specification and should be able to power the Bluetooth module. A rechargeable battery is also utilized to enable measurement when the machine is idle. The next stage of the project will be to build the Bluetooth module, with its associated Rogowski coils and temperature sensor, and to test the complete system in a VSD.

\section{Acknowledgements}

The research leading to these results has received funding from the Innovate UK technology programme. (Project reference number: 102155)

\section{References}

[1] P. Roberts, E. Abdi-Jalebi, R. McMahon and T. Flack, "Real-time rotor bar current measurements using bluetooth technology for a brushless doubly fed machine (bdfm)," Power Electronics, Machines and Drives, 2004 (PEMD 2004). Second International Conference on., vol. 1, no. 498, pp. 120-125, March 2004. 
[2] E. Abdi-Jalebi and R. McMahon, "Application of realtime rotor current measurements using Bluetooth wireless technology in study of the brushless doubly fed (induction) machine (bdfm)," Industry Applications Conference, 2006. 41st IAS Annual Meeting. Conference Recond of the 2006 IEEE, vol. 3, pp. 1557-1561, Oct 2006.

[3] E. Abdi, X. Wang, S. Shao, R. McMahon and P. Tavner, "Performance characterisation of brushless doubly-fed generator," Industry Applications Society Annual Meeting, 2008. IAS '08. IEEE, pp. 1-6, Oct 2008.

[4] E. Abdi-Jalebi, Modelling and Instrumentation of Brushless Doubly-Fed (Induction) Machines, $\mathrm{PhD}$ thesis, University of Cambridge, 2006.

[5] P. Roberts, A Study of Brushless Doubly-Fed (Induction) Machines: Contributions in Machine Analysis, Design and Control, PhD Thesis, Unviersity of Cambridge, 2004. 